\title{
A Study on Social Media Marketing of High-End Hotels in Sanya
}

\author{
Yanling Yu ${ }^{1}$, Suping Liu ${ }^{2}$ \\ ${ }^{1}$ Tourism Management College, University of Sanya, Sanya, China, 572000 \\ ${ }^{2}$ School of Tourism Management, Suzhou Institute of Trade \& Commerce, Sanya, China,215002
}

Keywords: social media; social media marketing; social media marketing effectiveness; high-end hotels in Sanya

\begin{abstract}
This paper introduces the definition of social media and social media marketing in the field of hospitality industry, and the current status of the development of hospitality industry in Sanya. WeChat and Weibo as the two main social media marketing tools utilized by hoteliers in Sanya are explained in details. This paper further analyzes the usage of social media marketing by high-end hotels in Sanya and provides suggestions to ensure the effectiveness of social media marketing for high-end hotels in Sanya. Both customers and messages should be the focuses of social media marketing campaign and the help of big data and Key Opinion Leaders should also be noticed. Wifi connection and convenient payment methods are also the key to successful social media marketing activities for high-end hotels in Sanya.
\end{abstract}

\section{Introduction}

Since its first appearance in 2004, social media has developed rapidly in the past 14 years. Many social media platforms and applications have emerged onto the market and people are becoming more and more attached to various social media platforms and applications, such as Facebook, Twitter and Instagram for the international community and Weibo and WeChat for the Chinese market. At the same time, they are becoming more and more influenced by contents emerging on social media, for example, opinions from family members and friends, Key Opinion Leaders as well as website celebrities. As a result, many businesses in the tourism sector are beginning to explore opportunities using social media to reach out to their existing and potential customers and promote their business (Inversini \& Sykes, 2013). Like other businesses, hotels and hotel groups, especially high-end hotels in Sanya are pioneers in this movement. Many high-end hotels in Sanya have set up official accounts on various social media platforms and carried out effective social media marketing campaigns. Nevertheless, not enough studies have been conducted to find out the mechanism of social media marketing in the field of hospitality industry.

\section{The Definition of Social Media and Social Media Marketing}

\subsection{The definition of social media}

Much discussion has been held about the definition of social media. As technology develops, social media also continues to evolve and the usage of social media changes and expands, so does the definition of social media. From different perspectives, many academics have proposed 30 different definitions of social media (Cohen, 2011), with some common characteristics and natures identified, including : 1) social media are online tools, applications, platforms and media, and therefore depend on information technology; 2) social media are peer-to-peer communication channels, which enables the interactive web's content creation, collaboration and exchange by participants and the public, facets which introduce substantial and pervasive changes to communication between organizations, communities and individuals; and, 3) social media link users to form a virtual community by using cross-platforms, and therefore affects people's behavior and real life. As an umbrellas term, social media includes many different platforms, such as social networking sites, customer review sites, content community sites, wikis, Internet forums and 
location-based social media, where people connect socially with the integration of information and communication technology, social interaction and the contribution of words, pictures, videos and audio (Zeng \& Gerritsen, 2014).

\subsection{The definition of social media marketing}

Social media marketing means a way of Internet marketing that utilizes social media platforms as a marketing tool. The ultimate goal of social media marketing is to offer content that Internet users will share through their social networks to help the business increase its brand reputation and widen consumer reach. With the rapid development of social media over the recent years, many countries, destinations and businesses have been gradually regarding social media as an important tool to market and promote their tourism industries and products, which has proven to be an excellent strategy (Fotis, 2012). Traditional marketing and promotional processes throughout the tourism sector have been feeling the challenge (Ye et al, 2011). Social media can offer new ways for tourism businesses and organizations to develop new marketing strategies. One excellent example is Tourism Australia. On its Facebook page, Australian tour operators can have the chance to list themselves in a 'things to do' section, which will enable them to reach out to millions of fans of the country. Meanwhile, the Australian National Online Strategy Committee developed the “Tourism e-kit" tutorial package, in which "Social Media for Tourism" is the major component (Tourism Queensland, 2012). As more businesses use social media sites in their marketing efforts, the marketing spending in social media is also increasing.

\section{Development Status of High-end Hotels in Sanya}

\subsection{Introduction to sanya and its high-end hotels}

Sanya, a tropical city located on the southern tip of Hainan island, is renowned for its superb weather, advanced tourism development and flock of high-end hotels. Known as "China's Florida" and "China's Hawaii", Sanya has 20-kilometer long stretches of beach. As the only tropical city across the coastline, it is definitely booming and packed with a lot of water sports such as snorkeling and jet-skiing, rainforest hiking, and innumerable hotels ranging from zero to five stars. According to a recent report by China Association of travel Services, Sanya became the top 1 destination for Chinese tourists during the 2018 Chinese New Year holiday. On 22 August 1996, the first 5-star hotel, Gloria hotel opened in Yalong Bay. After 13 years' operation, it transformed into MGM Grand Sanya. By the end of 2016, there are 42 star-rated hotels in Sanya, including 14 5-star hotels and 17 4-star hotels, providing 11853 rooms and 20478 beds to visitors. There are 4 hotel clusters in Sanya located along 4 different bay areas, including Yalong Bay, Haitang Bay, Sanya Bay and Dadonghai Bay, which gained room occupancy rate at 80.76\%, 83.69\%, 78.98\% and $77.99 \%$ respectively, and pushed average room rate up to 3754, 3041, 1696 and 1627 Chinese Yuan during the 2018 Chinese New Year holiday.

\subsection{New high-end hotels brands in greater Sanya}

Many luxurious hotels can be found here in Sanya from different domestic and foreign hotel groups, including Hilton, Marriott, InterContinental, Wyndham, Accor, Shangri-La, Hyatt, BTG Homeinn, Wanda, Narada, New Century and so on. Many well-known hotel brands prefer to choose Sanya as their gateway to the Chinese market and to release their brands for the first time. In 2018, more luxurious brands will enter Sanya, including Four Seasons and St. Regis in Haitang Bay and Autograph in Dadonghai Bay. Atlantis Sanya, the top hotel recently opened in Sanya, is the first Atlantis resort in China. Combining fantastic dinning and winning experience from wide selection of restaurants, revolutionary water play and exotic marine exhibits, Atlantis is believed to be a strong boost for Sanya's hospitality industry.

In greater Sanya area, more bays are also seeing more luxurious hotels, including Hilton in Qingshui Bay, Sheraton in Tufu Bay, Marriott in Xiangshui Bay, Ritz Carlton in Nanyan Bay and Grand Hyatt in Shenzhou Peninsula. 


\section{Hotel Social Media Marketing Methods}

\subsection{The history of hotel social media marketing}

Social media has transformed the way how hospitality industry interacts with its existing and potential consumers, which in turn changes the way how hotels do business and attract and retain customers. In the hospitality industry, social media marketing has become the new trend and more and more hotels are using social media to promote their products and services. Starwood was one of the first hotel companies to use social media marketing. Later on, they launched their multiple social media sites including Twitter, Facebook, Flickr, and blogging platforms, where consumers can post their travel experiences and win rewards. Other hotel groups, such as Hyatt and Marriott followed the trend as well and it has proven to attract more bookings through the reservation page from the official blog or Facebook fan pages, which in turn generated more revenue from the increased rooms sales.

\subsection{Introduction to WeChat and Weibo}

China, with the world's largest population at 1.357 billion, is also the largest market in the world when it comes to social media users. There are 618 million Internet users in China, or a 45.8 percent Internet penetration rate according to the China Internet Network Information Center. Top social media platforms in China are WeChat, Weibo, QQ, Qzone, Renren, Youku and LinkedIn, according to their individual monthly active users. Let us take a closer look at Wechat and Weibo which are mainly used by high-end hotels in Sanya.

WeChat, with more than 1 billion monthly active users, is the biggest social network in China, but it is also where people turn to book a room, order a taxi, make an appointment, do their banking, or even find a date. Hotels and hotel groups can create official accounts within WeChat - a little like apps. Some do this before they even set up an app of their own. Users can subscribe to the accounts and get promotions messaged directly to them or click in be taken to a shopping page. And the built-in payment system means if hotels and hotel groups can persuade a user to part with some cash, the process of making that transaction is pretty straight forward. And WeChat is a big reason QR Codes have been adopted so readily in China - technology that helps hotels and hotel groups get information to users as well as facilitate those payments. Also, while WeChat has been fairly conservative in the amount of advertising it allows on its platform, it is a very targeted way for hotels and hotel groups to reach people. Weibo, with more than 376 million monthly active users, is no longer considered just to be the Chinese version of Twitter. Weibo has become an important social media platform for companies seeking to engage consumers and advertise their products. Marketing campaigns on Weibo are critical for brands seeking to build interest and hype from consumers, and expand their Weibo follower base.

\subsection{The usage of social media marketing by hotels in Sanya}

Social media marketing is a common approach to reach consumers in hospitality industry. Hotels can market their products and services and provide updated information to their social media fans. The effectiveness of this form of social media marketing in creating awareness, interest, or behavioral intention has been quantitatively measured. Marriott's CEO, Bill Marriott's blog, On the Move (www.blogs.marriott.com) was started in 2007 and has generated more than \$5 million in bookings from people who clicked through to the reservation page from the blog. In December 2009, Hotel Indigo started a Tweet Away promotion, during which it offered about one million Priority Club points to its Twitter followers redeemable for hotel nights, retail gift cards, electronics and more.

High-end hotels in Sanya also adopt many inspiring social media marketing method, such as direct sales through Official WeChat account, direct sales through Weibo fans page, daily updates through Official WeChat account, daily updates from Weibo fans page, recommendations from KOL, and direct sales from third parties on social media platforms. Hotels also need to continue collecting data of existing and potential customers to learn their behaviour, preference, relationship 
with the brand and intention to purchase, so the hotels can draw their own customer profiles and pick up the right customers.

\section{Hotel Social Media Marketing Effectiveness}

\subsection{Importance of social media marketing effectiveness}

As more high-end hotels in Sanya establish presences on social media platforms, more marketing spending is required to maintain the smooth operation, in order to identify, attract, interest and retain hotel's target market, generate positive electronic word-of-mouth, increase sales, improve brand awareness, monitor brand reputation, educate and inform consumers and improve customer services. Among all social media sites, Facebook lead in social network advertising revenues and is estimated to tally $\$ 5.78$ billion in 2012, representing $72 \%$ of all social network advertising revenues (“Facebook social networks", 2011).

However, common concerns by high-end hotels in Sanya have also been identified, and one of them is how to ensure the effectiveness of the social media marketing (Leung, Bai \& Stahura, 2015).

\subsection{Measures to reassure social media marketing effectiveness}

To ensure the effectiveness, hoteliers need to address the issue from two aspects, customers and messages. On the customer side, hotels should study and reinforce their customers' social identity on their social media platforms through the formation of an online social community and create message contents conforming to the norms and value systems of their customers. On the message side, hotels should balance social media message format and carefully choose the best message format based on the message content and the purpose of the messages. In terms of message content, brand, product, and involvement messages should be the first choices of hotel Facebook messages. Hotels should avoid using promotion messages a lot (Leung, 2013).

Social media has been proven to be an effective marketing tool for high-end hotels in Sanya. In order to make sure the effectiveness, hoteliers need to pay special attention to finding the right target market with help of big data, to effectively convey effective message with effective format, to manipulate the involvement of Key Opinion Leaders and to realize actual transaction (Bayne \& Cianfrone, 2013). Social media marketing is a relatively new subject in the hospitality and marketing field. Only a few studies have been conducted on this subject. Future studies might be able to find more information on Social media marketing within the hospitality industry (Parra-López et al, 2011).

\section{Acknowledgement}

Research on Social Media Marketing Effectiveness of High-end Hotels in Sanya towards the International Market, project number: 2014YD41.

\section{References}

[1] Inversini A, Sykes E. An Investigation into the Use of Social Media Marketing and Measuring its Effectiveness in the Events Industry, Toxicology \& Applied Pharmacology, 2013, 239(1):46-54.

[2] Cohen, H. 30 social media definitions. Posted by Heidi Cohen on May 9, 2011 in actionable marketing Social media, 101, (Available from: http://heidicohen.com/ social-media-definition/. Accessed on 25 February 2013)

[3] Zeng, B., \& Gerritsen, R. What do we know about social media in tourism? a review, Tourism Management Perspectives, 2014,10:27-36.

[4] Fotis J, Buhalis D, Rossides N. Social media use and impact during the holiday travel planning process[A] // Information and Communication Technologies in Tourism 2012[C]. Vienna: 
Springer,2012:13-24.

[5] Ye Q, Law R, Gu B, et al. The influence of user-generated content on traveler behavior: An empirical investigation on the effects of e-word-of-mouth to hotel online bookings[J]. Computers in Human Behavior, 2011, 27(2):634-639.

[6] Leung, X. Y. The marketing effectiveness of hotel facebook pages: from perspectives of customers and messages, Proquest Llc, 2013, 305.

[7] Leung, X. Y., Bai, B., \& Stahura, K. A. The marketing effectiveness of social media in the hotel industry: a comparison of facebook and twitter. Journal of Hospitality \& Tourism Research, 2015, 39(2):57-88.

[8] Russell J. Evaluate the Effectiveness of Social Media Marketing on Hotels, Hospitality Management Review Student Journal at Sheffield Hallam University, 2010, 1.

[9] Bayne K S, Cianfrone B A. The effectiveness of social media marketing: the impact of facebook status updates on a campus recreation event, Recreational Sports Journal, 2013, 37(2):147-159.

[10] Parra-López E, Bulchand-Gidumal J, Gutiérrez-Ta?o D, et al. Intentions to use social media in organizing and taking vacation trips[J]. Computers in Human Behavior, 2011, 27(2):640-654. 